\title{
Lung function, genetics and socioeconomic conditions
}

\author{
Philip H. Quanjer
}

\begin{abstract}
Affiliation:
Department of Pulmonary Diseases and Department of Paediatrics-Pulmonary Diseases, Erasmus Medical Centre, Erasmus University, Rotterdam, The Netherlands.

\section{Correspondence:}

Philip H. Quanjer, Department of Pulmonary Diseases and Department of Paediatrics-Pulmonary Diseases, Erasmus Medical Centre, Erasmus University, Rotterdam, The Netherlands.

E-mail: pquanjeraziggo.nl
\end{abstract}

@ERSpublications

Genetics and epigenetics affect body frame, accounting for lung function differences between Europeans and Africans http://ow.ly/LUIff

It has long been known [1] that, when comparing subjects of the same age and height, African ancestry is associated with $12-20 \%$ smaller forced expiratory volume in $1 \mathrm{~s}\left(\mathrm{FEV}_{1}\right)$ and forced vital capacity (FVC) than European ancestry. Both smaller and larger differences have been reported in studies of other ethnic groups. This has led to numerous efforts to explain the underlying reason for these ethnic differences. In this issue of the European Respiratory Journal, Menezes et al. [2] present the results of a detailed and carefully conducted study that significantly advances our understanding. Because of the complexity of the problem and the large number of relevant publications, the references below are inevitably selective.

When assessing lung volumes, adjustment is conventionally made for standing height. As long as individuals have the same body frame, stature is a convenient and valid proxy for estimating lung volume. However, ethnicity affects body proportions: the Cormic index, i.e. the ratio of sitting height (a proxy for thoracic dimensions) and stature, differs systematically between ethnic groups [3]. Hence, ethnic differences in pulmonary function may be due to differences in body habitus. Indeed, most studies carried out in different ethnic groups confirm differences in lung volumes are associated with sitting height or Cormic index [4-12]. However, they explain only $41-53 \%$ of the disparity between white and African Americans $[9,13]$. Therefore, these anthropometric differences play a role but do not fully explain ethnic differences in lung volumes.

Exploring the possible genetic basis for the differences, skin colour or self-reported ethnicity is a poor indicator of African ancestry, because there is considerable ancestral admixture with genes from Europeans [14]. KUMAR et al. [15] were the first to investigate how much genetic ancestry contributes to differences in pulmonary function among self-identified African Americans. The degree of African ancestry was quantified by genotyping. Adjusting for age, height, sex, smoking and body mass index, they found a significant relationship between African ancestry and spirometry in adults; compared to $100 \%$ European ancestry, for each extra percentage point of African ancestry, the FEV1 and FVC were lower by 8 and $12 \mathrm{~mL}$ in males, and 6 and $5 \mathrm{~mL}$ in females. This appears to confirm the contribution of a genetic component to the disparity between African American and European ventilatory function, but there is a snag.

Ever since the pioneering work of Louis-René Villermé, the founding father of social epidemiology, there has been overwhelming evidence of the relationship between socioeconomic conditions (SEC) and growth

Received: April 022015 | Accepted after revision: April 132015

Conflict of interest: None declared.

Copyright @ERS 2015 
as well as mortality $[16,17]$. Against that background, the association between smaller lung volumes and lower SEC in African Americans is usually interpreted as evidence of "impaired" or "poor" lung function. Therefore, it has been suggested that the level of respiratory disadvantage and risk of mortality should be gauged by using spirometry prediction equations for people of European ancestry rather than ethnic-specific equations [18], on the basis that, if the SEC were to be the same, ethnic differences in lung volumes would vanish. This is in line with one perspective, i.e. that ethnicity is a sociopolitical construct that suggests genetic heterogeneity between groups [19]; alternatively, an opposing view is that there is still a role for genetics in explaining differences in lung function [15].

BReHM et al. [20] extended the study by Kumar et al. [15] in Puerto Rican children by including an extensive panel of potential confounders. Using genome-wide genotypic data, they concluded that African ancestry is associated with reduced FEV1 and FVC in Puerto Rican children independently of indicators of socioeconomic status, healthcare access or key environmental/lifestyle exposures. Genetic variants, early-life environmental/lifestyle factors or both, correlated with African ancestry, might influence lung development and growth during childhood in Puerto Rican subjects.

Because of the interrelations between ethnic group, SEC, physical growth and the effect of childhood disease on body development, it is difficult to untie this Gordian knot. Menezes et al. [2] now extend the study by BREHM et al. [20], which did not address differences in body habitus, by measuring stature, the Cormic index and chest circumference in 2869 Brazilians aged 30 years [2]. African ancestry was quantified by genotyping and a large panel of potential confounders were adjusted for. With the exception of chest circumference, anthropometric indices were inversely associated with African ancestry. In a subset of 1870 subjects, ethnic differences in FEV1 and FVC between subjects were more than halved after taking anthropometric variables into account; remaining differences still correlated negatively with the extent of African ancestry but were barely affected by SEC and other confounders, even though these were unfavourable for those with a higher proportion of African ancestry.

In humans, there is a cephalocaudal gradient of growth and development so that the limbs grow faster than other body segments from birth to about 10-12 years, making them vulnerable to adverse conditions in early childhood. Therefore, relatively short legs are a marker of adverse conditions in childhood in relation to factors such as SEC, infections, healthcare, nutrition and antioxidants [21]. However, paleontological findings show that as mankind moved out of sub-Saharan Africa, leg length relative to stature decreased in early Europeans [22]. African Americans still have relatively longer legs than their white counterparts [3]; this cannot be explained by a more favourable socioeconomic position and has been shown to have a genetic basis [23]. The findings of MenEzes et al. [2] reveal a pattern of genetic differences in body frame: the more completely body habitus is explained, the smaller the association of ethnic differences in lung volumes with SEC and lifestyle/health variables. HARIK-KHAN et al. [9] found that adjustment for sitting height rather than stature reduced the ethnic difference in FEV1 from $14 \%$ to $8 \%$ in girls, and from $14 \%$ to $6 \%$ in boys, with further reductions of $1 \%$ and $2 \%$, respectively, adjusting for SEC and other confounders. BREHM et al. [20] adjusted only for height; a household income $<\$ 15000$ was associated with a $3 \%$ smaller FEV1 and $4 \%$ smaller FVC. In the study by MenEzes et al. [2], only -10 to $+30 \mathrm{~mL}$ were accounted for by SEC and other confounders after adjustment for height, sitting height, chest circumference and percentage African ancestry.

There is much evidence that, in healthy subjects, ethnic differences in lung volumes are proportional rather than functional, as first suggested by Jere Mead [24]. Whereas the FEV1, FVC, residual volume (RV) and total lung capacity (TLC) differ between ethnic groups, there is no systematic difference in the FEV1/FVC ratio $[4,15,24-27]$ or RV/TLC ratio [4, 25, 27]. Similarly, the transfer factor of the lung for carbon monoxide (TLCO)/alveolar volume (VA) ratio does not differ between Europeans and East-Asians [28], nor are lung elastic properties different [29]. Although there are clear differences in FEV1 and FVC related to SEC, and between urban and rural populations, there is no such pattern for the FEV1/FVC ratio [30, 31]. Reports on differences in chest circumference are inconclusive, possibly because this index is highly associated with body mass and also, possibly, because of heterogeneity in measurement protocols. DAMON [24] reported a $20 \%$ smaller chest expansion in African than European Americans. Radiographic measurements show that internal chest dimensions differ proportionally between Europeans and Nigerians [32]; similar differences have been reported by others [29, 33, 34]. Remarkably, pulmonary function in Malagasy and Nigerian individuals does not differ from that of African Americans [35-37] in spite of a 10 -fold difference in the gross national income per capita based on purchasing power parity: Madagascar, \$1370; Nigeria, \$5360; USA, \$53750 (data for 2013 from [38]). Finally, Africans frequently outperform athletes with European ancestry in competitive sports, emphasising that their smaller lungs can meet the highest metabolic demands. Primates share a scalable lung design that even accommodates individuals with achondroplasia [39]. 


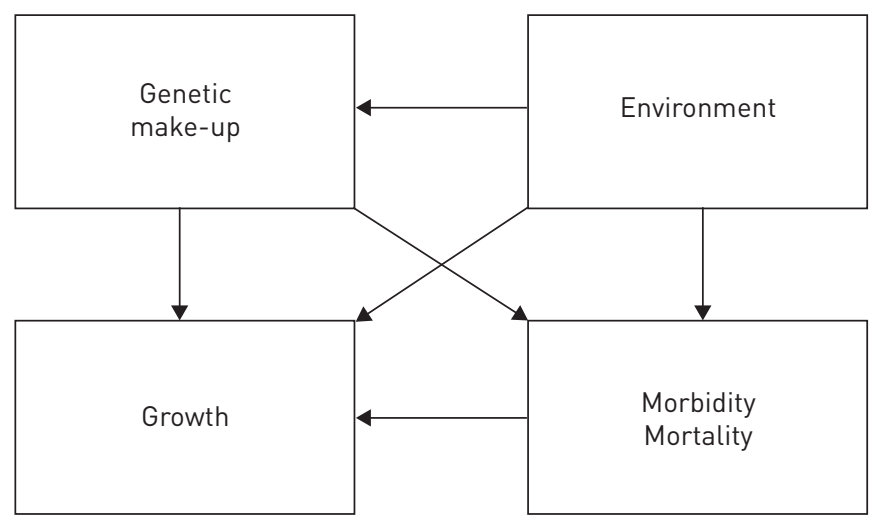

FIGURE 1 Genetic programming of growth may be epigenetically modified by interaction with the environment and also lead to a propensity to the development of disease. Adverse environmental conditions (e.g. malnutrition) may directly affect intrauterine and postnatal growth and development, or indirectly by inducing disease postnatally.

From the evidence above, it appears that genetic make-up and adverse conditions in early life affect the body frame and, hence, the relationship between anthropometric variables and lung volumes: the lung may be smaller than in Europeans but it is fully functional. Accounting for height, Cormic index and chest circumference in the study by Menezes et al. [2] did not fully explain the association of FEV1 and FVC with African ancestry, possibly because these indices do not fully account for the dimensions of the thoracic cage.

This does not explain the well-known association between low lung volumes, morbidity and mortality. Adverse conditions during early life lead to gene-environment interaction, inducing epigenetic changes. The fetus can be affected in utero; transgenerational inheritance occurs if that individual, or an adult male in whom that change is induced, transmits the epigenetic change to its germline [40]. Evidence of epigenetic changes was found in 50-year-old subjects whose mothers conceived during the 1944-1945 Dutch famine during the Second World War: there was more coronary heart disease, raised lipids, altered clotting and more obesity in those exposed to famine in early gestation compared to those not exposed; exposure in mid-gestation was associated with obstructive airway disease, microalbuminuria and reduced creatinine clearance; and in late gestation, with decreased glucose tolerance. This suggests that effects of malnutrition have an organ-specific time window during gestation [41]. In accordance with this, the association between a low FEV1 and mortality is most closely related to inflammatory mediators (21\%), coronary heart disease, stroke and diabetes (12\%), and lifestyle factors (10\%), with only a small contribution from SEC $(<3 \%)$ [42]. It therefore seems that genetic factors as well as conditions in early life lead to differences in body frame, affecting the relationship between stature and lung volumes, which are proportionally reduced. In addition, adverse conditions in early life are associated with morbidity and mortality, independently of conditions during adulthood. A putative representation of the interplay between the various factors is shown in figure 1 .

As regards clinical interpretation of lung function test results, broadly, the following lessons can be learned. Due to genetic differences in body frame, prediction equations for Europeans should not be applied to either African Americans or other non-European ethnic groups. Extensive human migration and intermarriage has led to ethnic admixture, which can lead to significant inaccuracies in predicted lung volumes based on self-reported ethnicity. However, because lung volumes differ proportionally between ethnic groups, this does not affect volume-adjusted indices, such as FEV1/FVC, RV/TLC and TLCO/VA. In countries where SEC, healthcare and nutrition are changing appreciably over time, body proportions will change in successive cohorts $[3,21]$, so that prediction equations for that region will need periodic updating [43]. When interpreting test results for subjects of mixed ethnicity, clinical decision making should prevail over strict reliance on the predicted limits of normal for lung volumes.

\section{References}

1 Gould BA. Investigations in the Military and Anthropological Statistics of American Soldiers. New York, Hurd and Houghton, 1869.

2 Menezes AMB, Wehrmeister FC, Hartwig FP, et al. African ancestry, lung function and the effect of genetics. Eur Respir J 2015; 45: 1582-1589.

3 Eveleth PB, Tanner JM. Worldwide variation in human growth. 2nd Edn. Cambridge, Cambridge University Press, 1990.

4 van de Wal BW, Erasmus LD, Hechter R. Stem and standing heights in Bantu and white South Africans: their significance in relation to pulmonary function values. S Afr Med J 1971; 45: 568-570. 
Miller GJ, Saunders MJ, Gilson RJ, et al. Lung function of healthy boys and girls in Jamaica in relation to ethnic composition, test exercise performance, and habitual physical activity. Thorax 1977; 32: 486-496.

6 Ong TJ, Mehta A, Ogston S, et al. Prediction of lung function in the inadequately nourished. Arch Dis Child 1998; 79: $18-21$.

7 Yap W-S, Chan C-C, Chan S-P, et al. Ethnic differences in anthropometry among adult Singaporean Chinese, Malays and Indians, and their effects on lung volumes. Respir Med 2001; 95: 297-304.

8 Harik-Khan RI, Fleg JL, Muller DC, et al. The effect of anthropometric and socioeconomic factors on the racial difference in lung function. Am J Respir Crit Care Med 2001; 164: 1647-1654.

9 Harik-Khan RI, Muller DC, Wise RA. Racial difference in lung function in African-American and White children: effect of anthropometric, socioeconomic, nutritional, and environmental factors. Am J Epidemiol 2004; 160: 893-900.

10 Bajo JM, Mangeaud A. Relationship between the lung function and anthropometric measures and indexes in adolescents from Cordoba, Argentina. Am J Hum Biol 2010; 22: 823-829.

11 Oloyede IP, Ekrikpo UE, Ekanem EE. Normative values and anthropometric determinants of lung function indices in rural Nigerian children: A pilot survey. Niger J Paediatr 2013; 40: 406-411.

12 Raju PS, Prasad KV, Ramana YV, et al. Influence of socioeconomic status on lung function and prediction equations in Indian children. Pediatr Pulmonol 2005; 39: 528-536.

13 Whitrow MJ, Harding S. Ethnic differences in adolescent lung function: anthropometric, socioeconomic, and psychosocial factors. Am J Respir Crit Care Med 2008; 177: 1262-1267.

14 Zakharia F, Basu A, Absher D, et al. Characterizing the admixed African ancestry of African Americans. Genome Biol 2009; 10: R141.

15 Kumar R, Seibold MA, Aldrich MC, et al. Genetic ancestry in lung-function predictions. N Engl J Med 2010; 363: $321-330$.

16 Villermé L-R. Mémoire sur la taille de l'homme en France [Report on the height of men in France]. Annales d'hygiène publique et de médecine 1829; I: 351-399.

17 Villermé L-R. Variétés. Assemblée générale du 3 août 1824 de l'Académie de Médecine. Lecture de "Considérations sur la mortalité comparative dans la classe indigente et dans la classe aisée". [Varieties. General Assembly of 3 August 1824 of the Academy of Medicine. Lecture on "Considerations on comparative mortality in the indigent class and the upper class"]. Archives Générales de Médecine 1824; 1:137-139.

18 Burney PGJ, Hooper RL. The use of ethnically specific norms for ventilatory function in African-American and white populations. Int J Epidemiol 2012; 41: 782-790.

19 Thomas D. Gene-environment-wide association studies: emerging approaches. Nature Rev Genet 2013; 11: 259-272.

20 Brehm JM, Acosta-Perez E, Klei L, et al. African ancestry and lung function in Puerto Rican children. J Allergy Clin Immunol 2012; 129: 1484-1490.

21 Cole TJ. Secular trends in growth. Proc Nutr Soc 2000; 59: 317-324.

22 Holliday TW, Falsetti AB. A Malinanew method for discriminating African-American from European-American skeletons using postcranial osteometrics reflective of body shape. J Forensic Sci 1999; 44: 926-930.

23 Chan Y, Salem RM, Hsu Y-HH, et al. Genome-wide analysis of body proportion classifies height-associated variants by mechanism of action and implicates genes important for skeletal development. Am J Hum Genet 2015 [In press DOI: 10.1016/j.ajhg.2015.02.018].

24 Damon A. Negro-white differences in pulmonary functional vital capacity, timed vital capacity and expiratory flow rate. Hum Biol 1966; 38: 381-393.

25 Rossiter CE, Weill H. Ethnic differences in lung function: evidence for proportional difference. Intern J Epidemiol 1974; 3: 55-61.

26 Quanjer PH, Stanojevic S, Cole TJ, et al. Multi-ethnic reference values for spirometry for the 3-95 years age range: the global lung function 2012 equations. Eur Respir J 2012; 40: 1324-1343.

27 Johannsen ZM, Erasmus LD. Clinical spirometry in normal Bantu. Am Rev Respir Dis 1968; 97: 585-597.

28 Korotzer B, Ong S, Hansen JE. Ethnic differences in pulmonary function in healthy nonsmoking Asian-Americans and European-Americans. Am J Respir Crit Care Med 2000; 161: 1101-1108.

29 Donnelly PM, Yang T-S, Peat JK, et al. What factors explain racial differences in lung volumes? Eur Respir J 1991; 4: $829-338$

30 Gray LA, Leyland AH, Benzeval M, et al. Explaining the social patterning of lung function in adulthood at different ages: the roles of childhood precursors, health behaviours and environmental factors. $J$ Epidemiol Community Health 2013; 67: 905-911.

31 Sonnappa S, Lum S, Kirkby J, et al. Disparities in pulmonary function in healthy children across the Indian urban-rural continuum. Am J Respir Crit Care Med 2015; 191: 79-86.

32 Paul R, Fletcher GH, Addison G. A comparative study between Europeans and Africans in the mining industry of Northern Rhodesia. Med Proc 1960; 6: 69-74.

33 Dufétel P, Sambiani K, Togbey K, et al. Particularités des volumes pulmonaires et débits expiratoires observées chez l'adulte noir Africain [Characteristics of lung volume and expiratory flow seen in black Africans adults]. Rev Mal Respir 1990; 7: 215-222.

34 Obikili EN, Okoye IJ. Transverse thoracic diameter in frontal chest radiographs of an adult Nigerian population. West Afr J Med 2006; 25: 186-189.

35 Glew RH, Kassam H, Van der Voort J, et al. Comparison of pulmonary function between children living in rural and urban areas in northern Nigeria. J Trop Pediatr 2004; 50: 209-216.

36 Arigliani M, Altomare M, Mottini G, et al. Lung function and nutritional status in urban Malagasy children. Eur Respir J 2014; 44: Suppl. 58, 192.

37 Ratomaharo J, Linares-Perdomo O, Collingridge DS, et al. Spirometric reference values for Malagasy adults aged 18-73 years. Eur Respir J 2015; 45: 1046-1054.

38 The World Bank. GNI per capita, PPP (current international \$). http://data.worldbank.org/indicator/NY.GNP. PCAP.PP.CD

39 Stokes DC, Wohl ME, Wise RA, et al. The lungs and airways in achondroplasia. Do little people have little lungs? Chest 1990; 98: 145-152. 
40 Heard E, Martienssen RA. Transgenerational epigenetic inheritance: myths and mechanisms. Cell 2014; 157: 95-109.

41 Roseboom TJ, Painter RC, van Abeelen AF, et al. Hungry in the womb: what are the consequences? Lessons from the Dutch famine. Maturitas 2011; 70: 141-145.

42 Sabia S, Shipley M, Elbaz A, et al. Why does lung function predict mortality? Results from the Whitehall II Cohort Study. Am J Epidemiol 2010; 172: 1415-1423.

43 Quanjer PH, Kubota M, Kobayashi H, et al. Secular changes in relative leg length confound height-based spirometric reference values. Chest 2015; 147: 792-797. 